\title{
Rachel Mamlok-Naaman, Ingo Eilks, George Bogner and Avi Hofstein: Professional Development of Chemistry Teachers - Theory and Practice, Royal Society of Chemistry: Croydon (UK), 2018, 203 pp.: ISBN: 9781782627067
}

Reviewed by Silvija MARKIC ${ }^{1}$

In recent years, the focus in science education research in general, and chemistry education research in particular, has shifted from students to teachers. This is reasonable, since teachers are the key factor for changes in the classroom. Thus, the professional development of teachers in general and chemistry teachers in particular is an essential element, if not the key element, for effective and improved chemistry teaching and learning. As written on the cover of the present book, "Professional development aims to keep chemistry teaching up-to-date and to

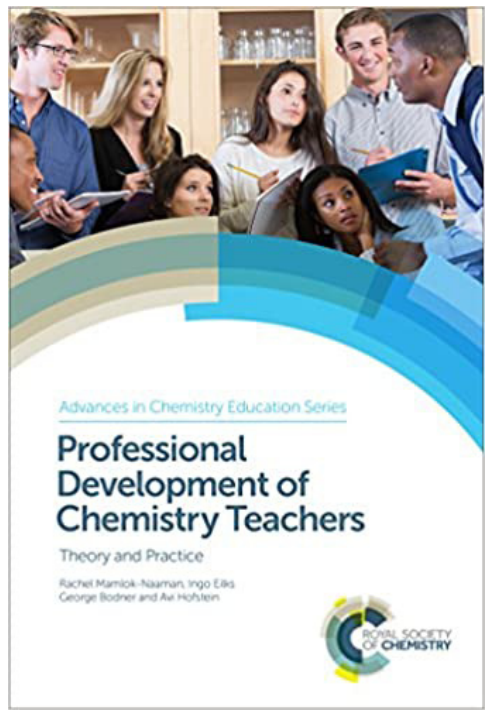
make it more meaningful, more educationally effective, and better aligned to current requirements".

The authors of the book have extensive experience working as science/ chemistry teachers in school, but all four of them are also successful chemistry education researchers who have been working on the topic of professional development for a long time in their careers.

First, it must be said that this book is not a collection of different chapters written by different scholars and edited by the four persons named in the tittle of this review. The four authors wrote the book based on their own experience and research, while also undertaking a thorough international literature review.

$1 \quad$ Ludwigsburg University of Education, Institute for Science and Technology, Germany; markic@ph-ludwigsburg.de. 
In general, the book presents different models and examples of professional development for chemistry teachers that stem from different countries, and thus from different cultures and education systems. Furthermore, the authors present both theory and practice, focusing on current issues in modern chemistry education. When talking to chemistry teachers about their professional development, they usually mention the obstacles involved. In this book, the authors also focus on issues that can have a negative impact on successful professional development, providing ideas and advice on how to manage these issues.

The authors begin with an explanation of the need for the book. The first chapter is called Introduction - Issues Related to the Professional Development of Chemistry Teachers. In this part, different fields of chemistry teaching are presented, as well as approaches to the preservice education of chemistry teachers. From here, the consequences for continuous professional development are drawn.

The second chapter, Understanding the Cognitive and Affective Aspects of Chemistry Teachers' Learning and Professional Development, presents the theory of this topic. The chapter is based on studies on teachers' knowledge, skills, attitudes and beliefs, starting from the three professional knowledge domains: pedagogical knowledge (PK), content knowledge (CK) and pedagogical content knowledge (PCK). The domains of professional growth (personal, practical, external and domain of consequences) are also discussed.

Each of the subsequent chapters has a similar structure. First, the theory related to each approach is discussed, followed by two examples from different countries.

The third chapter is entitled Top-Down Approaches for Chemistry Teachers' In-Service Professional Development - From Basic to Advanced. It presents different sources of information resources for chemistry teachers, such as traditional media, online courses and workshops. Challenges and resources for professional development from the point of view of the USA are presented, as well as a top-down, long-term approach in three cases from Israel.

The following chapter focuses on Cases of Bottom-up Professional Development for Chemistry Teachers. The idea is to encourage chemistry teachers to develop ownership of curriculum innovation. After presenting the theory, the practice is illustrated by the example of the PROFILES project and teachers' professional learning communities.

The fifth chapter discusses Action Research as a Philosophy for Chemistry Teachers' Professional Development and Emancipation. The examples report on action research work in Israel, and on twenty years of a curriculum development project by a group of chemistry teachers in Germany, based on the participatory action research model. 
Starting with the following chapter, Mamlok-Naaman, Eilks, Bodner and Hofstein focus on modern issues and topics concerning the professional development of chemistry teachers.

The next chapter (Chapter 6) is based on theory regarding Teacher Professional Development for Society, Sustainability, and Relevant Chemistry Education. The authors present the roots of society-oriented secondary chemistry education and discuss three dimensions of relevant science education. Issues related to the "chemistry for all" approach are discussed, and the importance of including social views on chemistry teaching and teacher education are presented. An example of a lesson unit on sustainable development is described.

Chemistry teaching and learning is not possible without a laboratory and practical work. Chapter 7, Professional Development of Chemistry Teachers to Teach Effectively in the Chemistry Laboratory, focuses on and discusses this topic. The authors present certain skills that chemistry teachers need to possess in order to teach chemistry effectively in laboratory settings. One of the foci is the development of inquiry-type high-order learning and thinking skills. In the last part of the chapter, the authors present an example of professional development of teachers to teach in the inquiry chemistry laboratory.

Chapter 8 is about the Continuous Professional Development of Chemistry Teachers to Incorporate Information and Communication Technology in their teaching. The chapter first reflects on the influence of modern ICT on chemistry teaching and learning, drawing implications for chemistry teacher education and professional development.

The penultimate chapter (Chapter 9) gives advice on How to Educate Chemistry Teachers to Become Leaders. A programme aimed at the long-term development of teachers is presented. The authors give guidance on how to prepare chemistry teachers to become educational leaders.

The last chapter (Chapter 10) summarises the general ideas of the book and points out further directions on the topic of the professional development of chemistry teachers. In addition, for "quick readers", the authors provide a summary after each chapter.

The book is intended for researchers and educators, to help them better understand the teachers' role in good and effective chemistry teaching. Although I agree with this, I would like to add that I see the value - and also importance - of this book for chemistry teachers, as well. While reading this book, I think teachers will be able to understand and reflect on the importance of their work and its influence on students, and thus on our future generations. Furthermore, it can be informative for chemistry teachers to see the different models of professional development, which most of them are probably 
unfamiliar with. As well as providing a good overview, it offers teachers an opportunity to choose a suitable model for themselves. Thus, I would highly recommend that chemistry teachers, too, read this book. 